Eur Neurol 1993:33:397-398

\begin{tabular}{|l|l|l|}
\hline F. & Federico & Micheli \\
\hline M. & Clara & Scorticati \\
\hline R. & Ralph & Pikielny \\
\hline C. & Cristina & Zurru \\
\hline E. & Mabel & Gatto \\
\hline
\end{tabular}

Servicio de Neurologia, Hospital de Clinicas 'Jose de San Martin', Buenos Aires, Argentina

\title{
Pachymeningeal Thickening in Rheumatoid Arthritis
}

\section{Key Words}

Rheumatoid arthritis

Pachymeningitis

Federico Micheli, Olleros 2240, 1426 Buenos Aires (Argentina)

Though infrequent, lepto- [ 1 ] and pachymeningeal fibrosis may develop secondary to a diversity of disorders or manifest in the idiopathic form.

Here we present a 56-year-old patient who developed pachymeningeal thickening presumably due to pachymeningitis after a 15 -year history of seropositive erosive nodular rheumatoid arthritis (RA).

He presented a progressive left hearing loss, swallowing difficulties and dysphonia in the absence of headache over the last 4 years.

Although fundus oculi were normal and visual fields full, there was marked right proptosis with downward and outward deviation accompanied by facial hyperesthesia with paresis of the masticatory muscles, lack of palate excursion with absence of the gag reflex and vocal chord paralysis, all on the right side. The only relevant finding on the contralateral side was a sensorineural hearing loss and vestibular paresis.

Erythrocyte sedimentation rate was elevated and X-rays ofhands and cervical spine were consistent with RA changes. CT scan 

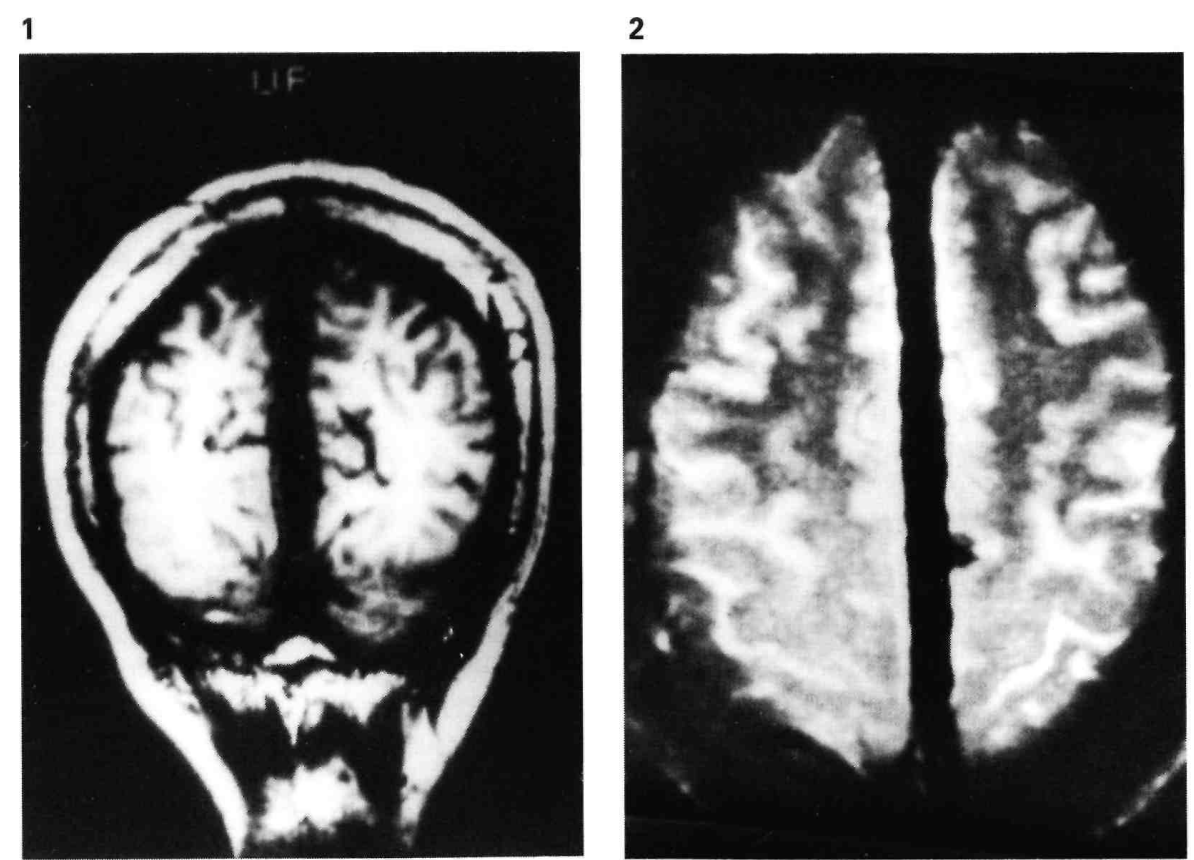

Fig. 1. Tli-weighted coronal MRI showing meningeal and falx thickening. Fig. 2. T2-weighted transaxial MRI disclosing marked falx thickening.

\section{1993 S. Karger AG, Basel}

$\$ 3.75 / 0$

showed dural enhancement with hypertrophy mainly in tentorium cerebelli and falx suggestive of thickened meninges and compatible with pachymeningitis. However, although meningeal biopsy showed marked thickening, microscopy disclosed fibrous tissue with no signs of inflammation, vasculitis or caseating granulomas. MRI confirmed meningeal thickening and pinpointed hy-pointense T1-hyperintense T2-weighted bilateral thalamic foci consistent with ischemia (fig. 1,2). No treatment was given and at 3 years' follow-up the patient's condition was unchanged.

Central nervous system involvement in RA is indeed rare [2] and only 17 cases of

pachymeningitis have so far been reported [2-6]. Neurological evaluation including gallium and technetium scintillography, CT scanning and MRI were only available in 4 of the above [2-5].

Although at necropsy most cases of RA associated with pachymeningitis disclosed rheumatoid nodules throughout the dura [6], such information may be missed when only biopsy material is available.

Recognized etiological factors such as trauma [7], toxins [7], metabolic disorders [8] and infections including tuberculosis [9], syphilis [9] and fungi [10] were carefully searched for but found absent in our patient, so that the meningeal involvement was reliably ascribed to RA. 
The absence of headache which has characterized most cases of pachymeningitis whatever its etiology and the spontaneous arrest in clinical progress are noteworthy.

Though several therapies have been employed to date, steroids seem the only effective medication, but only to alleviate headache since fibrotic reaction proceeds unchecked [1]

In contrast, no treatment was given to our patient, and at 3 years' follow-up the overall clinical picture remained unchanged.

\section{References}

1 Chalif D, Duchen LW, Marsma I, Hayward R: Progressive leptomeningeal fibrosis: A clinico-pathological case report. J Neurol Neurosurg Psychiatry 1983;46:261-265.

2 Beck DO, Corbett JJ: Seizures due to central nervous system rheumatoid meningovasculitis. Neurology 1983;33:1058-1061.

3 Yuh WTC, Drew JM, Rizzo M, Ryalıs TJ, Sato Y, Bell WE: Evaluation of pachymeningitis by contrast-enhanced MR imaging in a patient with 1990;11: 1247-1248.

Allison DJ, Marano GD: Computed tomography of rheumatoid pachymeningitis. AJNR 1985;6:976-977.

5 Higgins WL, Marano GD: Gallium imaging of rheumatoid pachymeningitis. Clin Nucl Med 1985;5:350-351.

6 Jackson CG, Chess RL, Ward JR: A case of rheumatoid nodule formation within the central nervous system and review of the literature. J Rheumatol 1984, 11.237-240.

WE. Chronic pachymeningitis. Report of a case and review of the literature. Arch Neurol Psychiatry 1949;62:383-411.

8 Paulson GW, Heagher JN, Brukhart J: Spinal pachymeningitis secondary to mucopolysaccharidosis. Case report. J Neurosurg 1974;41: 618-

9 Smith BH: Infections of the cranial dura and the dural sinuses: Part 1; in Vinken PJ, Bruyn GW (eds): Infections of the Nervous System. Part 1: Handbook of Clinical Neurology. New York, North Holland Publishing Company, 1978, vol 33, pp 149-182.

10 Sellby R: Pachymeningitis secondary to Al-lescheria boydii. Case report. J Neurosurg 1972;36:225-227.

398

Micheli/Scorticati/Pikielny/Zurru/Gatto

Rheumathoid Arthritis
Pachymeningeal Thickening in 